\title{
Papers
}

\section{PCR-ELISA for the early diagnosis of invasive pulmonary aspergillus infection in neutropenic patients}

\author{
M E Jones, A J Fox, A J Barnes, B A Oppenheim, P Balagopal, G R Morgenstern,
} J H Scarffe

Manchester Public Health Laboratory, Withington Hospital, Manchester, UK

$M$ E Jones

A J Fox

A J Barnes

B A Oppenheim

North West Lung Centre, South Manchester University Hospitals NHS Trust, Wythenshawe, Manchester, UK

P Balagopal

Christie Hospital NHS Trust, Withington, Manchester, UK:

Department of

Haematology

G R Morgenstern

Department of Medical Oncology

J H Scarffe

Correspondence to:

Dr A J Barnes, Manchester Public Health Laboratory, Withington Hospital,

Manchester M20 2LR, UK

Accepted for publication 1 June 1998

\begin{abstract}
Aim-To evaluate a newly developed aspergillus mitochondrial gene PCR-ELISA assay for the early diagnosis of invasive pulmonary aspergillosis (IPA) in neutropenic patients.

Methods-The aspergillus mitochondrial gene was chosen for the amplification target for use with a solution hybridisation assay with colorimetric end stage detection in microtitre plate format (PCRELISA). The study group comprised neutropenic patients undergoing febrile episodes not responding to standard antibacterial antibiotics. Patients underwent computed tomography and bronchoscopy. Bronchoalveolar lavage (BAL) fluids were examined by culture and PCR.

Results-The aspergillus mitochondrial gene PCR-ELISA was both sensitive $(100 \%)$ and specific $(100 \%)$ for IPA in neutropenic patients. All 12 patients with definite or probable IPA had PCR positive BAL fluids. None of the patients with undiagnosed or confirmed infections of other aetiologies were mitochondrial PCR positive. Speciation based upon amplicon size difference was possible.

Conclusions-Aspergillus mitochondrial DNA PCR-ELISA on BAL fluid is useful in the early diagnosis of IPA in neutropenic patients alone or, potentially, as an indication for thoracic computed tomography.

(f Clin Pathol 1998;51:652-656)
\end{abstract}

Keywords: aspergillosis; PCR-ELISA

Invasive fungal infections are an increasingly important cause of morbidity and mortality, particularly in cancer patients but also in other vulnerable groups. The most common opportunistic fungal infections are caused by candida and aspergillus species. The incidence of infection from both these has risen steadily in the last decade, with a 20 -fold increase in the incidence of candidaemia in one American centre, ${ }^{1}$ and a 14-fold increase in the incidence of invasive aspergillosis on the basis of a comprehensive necropsy study by Groll et al. ${ }^{2}$ Invasive disease caused by Aspergillus spp presents particular diagnostic challenges, and established disease carries a high mortality. ${ }^{3-6}$ In patients undergoing treatment for haematological malignancies, prolonged periods of profound neutropenia constitute a major risk factor for the development of invasive pulmonary aspergillosis (IPA). Optimising the diagnosis of IPA is an important goal, offering the possibility of the early initiation of aggressive antifungal treatment, which remains the key to a favourable outcome. ${ }^{134}$

Unfortunately, the diagnostic tools currently available are imperfect. The clinical features of early IPA may be as non-specific as neutropenic fever, and the plain chest radiograph may be initially normal. A definitive diagnosis of IPA can be made only after open lung biopsy, histology demonstrating tissue invasion by fungal hyphae and ideally, concomitant isolation of Aspergillus spp. Although regarded as the gold standard, open lung biopsy may fail to reveal the infection in at least $20 \%$ of cases. ${ }^{7}$ The discussion about sensitivity of open lung biopsy is often academic, because most leukaemic patients at risk of IPA are thrombocytopenic and unfit for this invasive approach. However, fibreoptic bronchoscopy with bronchoalveolar lavage is well tolerated. Isolation of Aspergillus spp from bronchoalveolar lavage (BAL) fluid can take several days, and a positive culture is obtained from only $50-59 \%$ of patients with tissue proven IPA. ${ }^{8}$ Fungaemia caused by aspergillus is rarely detected, ${ }^{10}$ although the pathogen disseminates to distant sites such as the brain and kidney, particularly in patients who have received high dose corticosteroid treatment. The low sensitivity of conventional culture methods for aspergillus in the neutropenic host has fuelled considerable interest in the area of non-culture diagnosis. Aspergillus antigen detection has previously lacked sensitivity, but a recently developed sandwich enzyme linked immunosorbent assay (ELISA) for detection of galactomannan polysaccharide antigen has facilitated the detection of low levels of circulating antigen in those patients at risk of IPA. ${ }^{11}$ Other serological techniques are hampered by the poor antibody responses mounted by neutropenic patients. ${ }^{12}$ One investigation identified as useful in the investigation 
of patients at risk for IPA is high resolution computed tomography of the thorax, with two specific radiological features-the "halo" sign, and "air crescent" sign — being identified as highly suggestive of IPA in the appropriate clinical setting. ${ }^{13} 14$

The polymerase chain reaction (PCR) has considerable potential for the early diagnosis of infection and may be particularly useful for infections such as IPA. Several PCR assays have been described for the detection of Aspergillus spp using a variety of fungal gene targets. ${ }^{15-17}$ Given the ubiquitous nature of Aspergillus spp, environmental sources represent a constant potential source of contamination for sensitive DNA amplification techniques. Furthermore, patients at risk of developing IPA may be colonised with Aspergillus spp. ${ }^{9}$ It is therefore essential for the accurate diagnosis of IPA to distinguish between colonisation and true invasive disease.

The development of PCR assays for the specific sensitive and accurate detection and diagnosis of IPA include Southern hybridisation steps to provide confirmation and increased sensitivity which requires significant additional time. The development of PCR assays for accurate routine early diagnosis of infections such as IPA requires the development of robust assays which provide maximum accuracy and sensitivity. The selection of primer and probe sequences for PCR assay development and end stage detection methods for PCR amplicon detection can have a major influence on assay performance. ${ }^{18}$

This paper describes the development of a sensitive and specific aspergillus mitochondrial DNA PCR combined with a solution hybridisation assay in a microtitre plate format with colorimetric end stage detection (PCR-ELISA). This technique permits the detection of Aspergillus spp DNA in BAL specimens, and provides a tool for the diagnosis of IPA.

\section{Methods}

STUDY GROUP

The study was based on immunocompromised patients undergoing treatment for haematological malignancies at risk of developing IPA. Patients underwent bronchoscopy to obtain BAL fluid at the time of a febrile episode which failed to respond to broad spectrum antibiotics. BAL specimens were processed using standard methods for the isolation of bacteria, fungi, and viruses, and examined using the PCR-ELISA. Patients with suspected IPA underwent high resolution computed tomography of the thorax. Weekly routine surveillance nasal cultures for aspergillus colonisation were performed.

FUNGAL DNA ISOLATION

DNA was isolated from several aspergillus species-Aspergillus fumigatus (NCPF 2140), Aspergillus flavus (NCPF 2008), and Aspergillus niger (NCPF 2190); other fungal pathogens used included Candida albicans and Torulopsis glabrata (both clinical isolates). DNA was also obtained from other organisms considered potential respiratory pathogens including human cytomegalovirus (AD169), adenovirus, herpes simplex virus I and II (Sigma Biosciences, Poole, UK), and clinical isolates of Pseudomonas aeruginosa, Escherichia coli, Haemophilus influenzae, Streptococcus pyogenes, and Streptococcus agalactiae. DNA was isolated from the fungal organism following culture in Sabouraud liquid medium (Oxoid; Unipath, Basingstoke, UK) for 72 hours at $30^{\circ} \mathrm{C}$. After centrifugation for five minutes at $14000 \mathrm{~g}$ the mycelial mat was washed in TE buffer (Tris HCL $10 \mathrm{mM}$ plus EDTA $1 \mathrm{mM}$ ) and resuspended in lysis buffer (250 mM EDTA plus $0.1 \mathrm{M}$ sodium maleate, $\mathrm{pH}$ 5.5) with the addition of the following per $\mathrm{ml}$ of lysis buffer: Novozym 234 (Calbiochem, Nottingham, UK) (5 mg), chitinase (Sigma) ( $1 \mathrm{mg}), \beta$-glucoronidase (Sigma) $(1 \mathrm{mg})$; the mixture was then incubated for two hours at $30^{\circ} \mathrm{C}$. This was followed by the addition of $100 \mathrm{ml}$ proteinase $\mathrm{K}(2 \mathrm{mg} / \mathrm{ml}), 20 \mu \mathrm{l}$ sarkosyl $30 \%$ (wt/vol), $50 \mu \mathrm{l} 1 \mathrm{M}$ Tris-HCl, $\mathrm{pH} 7.6$, and further incubation for one hour at $65^{\circ} \mathrm{C}$. Contaminating proteinaceous material was removed by the addition of $200 \mu$ l Puregene protein precipitation solution (Gentra Systems Inc, Minneapolis, Minnesota, USA) to the cell lysate according to manufacturer's instructions. The fungal DNA was washed once by ethanol precipitation and the final DNA pellet resuspended in $100 \mu \mathrm{l}$ of injectable water.

ISOLATION OF DNA FROM MICROORGANISMS

Each organism was cultured overnight on solid medium, several colony forming units (CFU) were suspended in $500 \mu \mathrm{l}$ of lysis buffer (200 $\mathrm{mM}$ Tris- $\mathrm{HCl}, 0.5 \mathrm{M} \mathrm{NaCl}, 10 \mathrm{mM}$ EDTA, $1 \% \mathrm{SDS}), 50 \mu \mathrm{l}$ proteinase $\mathrm{K}(2 \mathrm{mg} / \mathrm{ml})$ were added and the suspension incubated at $65^{\circ} \mathrm{C}$ for one hour. The nucleic acids were extracted once with phenol-chloroform, precipitated, and resuspended in $100 \mu \mathrm{l}$ in sterile injectable water. For isolation of streptococcal DNA the suspensions were treated with $1 \mu$ of lysozyme $(20 \mathrm{mg} / \mathrm{ml})$ at $37^{\circ} \mathrm{C}$ for 15 minutes before proteinase $\mathrm{K}$ treatment as above.

Purified viral DNA from the respiratory viral pathogens herpes simplex I and II, cytomegalovirus, and adenovirus was obtained from Sigma Biosciences.

EXTRACTION OF NUCLEIC ACID FROM CLINICAL SAMPLES

Total nucleic acid was extracted from BAL by adding $200 \mu \mathrm{l}$ of BAL fluid or serum to $100 \mu \mathrm{l}$ of lysis buffer (200 mM Tris- $\mathrm{HCl} \mathrm{pH} \mathrm{8,} \mathrm{0.5} \mathrm{M}$ $\mathrm{NaCl}, 10 \mathrm{mM}$ EDTA, $0.5 \%$ Tween $20,0.5 \%$ Nonidet P-40); this was followed by the addition of $100 \mu \mathrm{l}$ of proteinase $\mathrm{K}$ buffer (2 $\mathrm{mg} / \mathrm{ml}$ ) and incubation for one at $65^{\circ} \mathrm{C}$. The nucleic acid was extracted once with phenolchloroform, precipitated with ethanol, and resuspended in $50 \mu \mathrm{l}$ of sterile injectable water.

The contamination prevention measures which were used throughout included the performance of extraction, amplification, and detection in separate enclosed rooms, and the use of dedicated pipettes for each step. Water controls were included as every second sample, which were processed simultaneously with clinical samples. 
ASPERGILLUS DNA DETECTION BY PCR

PCR for the detection of aspergillus DNA was carried out using oligonucleotide primers and a 5 'biotin labelled internal oligonucleotide probe chosen from the aspergillus mitochondrial (mt) DNA sequence (GenBank accession number L37095). The primer and probe sequences were as follows (nucleotide position):

Forward primer (P1): 5'GAAAGGTCAGGTGTTCGAGTCA'3, (804-826)

Reverse primer (P2): 5'CTTGGTTGCGGGTTTAGGGATT'3 (916-938)

Probe: 5'GTAACATAGATGGCTCATGACCA'3 (879-901).

Greater PCR assay sensitivity may be achieved through improved primer design; therefore the primer and probe sequences were designed using the "Primer Select" software package (DNASTAR Inc, Madison, Wisconsin, USA).

PCR ASSAY

The reaction conditions were optimised for the primer set. The PCR reaction mixture contained $25 \mathrm{mM}$ Tris- $\mathrm{HCl} \mathrm{pH} 8.4,17 \mathrm{mM}$ $\left(\mathrm{NH}_{4}\right)_{2} \mathrm{SO}_{4}, 0.5 \mathrm{mM} \beta$ mercaptoethanol, $0.1 \%$ gelatin, $100 \mathrm{mM}$ PCR DIG labelling mix containing $2 \mathrm{mM}$ dATP, dCTP, dGTP each, 1.9 $\mathrm{mM}$ dTTP, $0.1 \mathrm{mM}$ digoxigenin-11-dUTP (Boehringer Mannheim, Lewes, UK), 2.5 units of Taq DNA polymerase (Gibco BRL, Paisley, $\mathrm{UK}$ ), $2 \mathrm{mM} \mathrm{MgCl}_{2}$, and the mitochondrial gene primers $(2.8 \mathrm{mM})$.

Amplification of the mitochondrial gene fragment involved denaturation for five minutes at $94^{\circ} \mathrm{C}$ followed by 40 cycles of denaturation at $94^{\circ} \mathrm{C}$ for 30 seconds, annealing at $58^{\circ} \mathrm{C}$ for 30 seconds, and extension at $72^{\circ} \mathrm{C}$ for 30 seconds, followed by a final incubation at $72^{\circ} \mathrm{C}$ for 10 minutes.

PCR products were detected using a solution hybridisation based microtitre plate assay. The PCR-ELISA was carried out according to the manufacturer's protocol (Boehringer Mannheim). Briefly; the PCR products were denatured and hybridised to a streptavidin coated microtitre plate using a specific biotinylated oligonucleotide capture probe. After binding of an antidigoxigenin antibody labelled with peroxidase to the amplified DNA, the complex was visualised by adding 2,2'-azino-di-(ethylbenzthiazolin) sulphonate (ABTS), and the optical density of the colour reaction was subsequently determined by spectrophotometry.

DNA samples were examined for PCR inhibition by amplification of a human $\beta$ globin gene fragment (14), giving rise to a $268 \mathrm{bp}$ product identified by $3 \%$ (3:1) Nusieve agarose gel.

PCR-ELISA CUTOFF

The optical density (OD) cutoff was calculated to determine positive, negative, and equivocal PCR-ELISA results using negative clinical samples. The ABTS substrate absorbance was measured at $405 \mathrm{~nm}$ and $492 \mathrm{~nm}$. To give a negative cutoff, two standard deviations were added to the mean OD of all the negative samples tested. The equivocal range was desig- nated between the negative cutoff and the mean of the negative samples plus four standard deviations. Samples which fell within the equivocal range were retested. Samples with $\mathrm{OD}$ values $\geqslant 4 \mathrm{SD}$ above the negative cut off were considered positive.

\section{SENSITIVITY STUDIES}

To determine the lower limit of detection of aspergillus mt DNA, PCR-ELISA dilutions of A fumigatus DNA in water at $54 \mathrm{ng} / \mathrm{ml}, 5.4$ $\mathrm{ng} / \mathrm{ml}, 60 \mathrm{pg} / \mathrm{ml}, 6 \mathrm{pg} / \mathrm{ml}, 60 \mathrm{fg} / \mathrm{ml}, 6 \mathrm{fg} / \mathrm{ml}$, and $0.6 \mathrm{fg} / \mathrm{ml}$ were subject to amplification in the $\mathrm{mt}$ PCR-ELISA. The test sensitivity for detection of aspergillus DNA in BAL samples was based upon proven and probable cases of IPA.

SPECIATION OF ASPERGILLUS BY MITOCHONDRIAL GENE PCR

Sequence variation in the mitochondrial gene allows the identification of different aspergillus species, based upon size variation of the mitochondrial gene PCR amplicons. Mitochondrial gene amplicons for different aspergillus species and clinical specimens were sized by agarose gel electrophoresis.

\section{CASE DEFINITIONS}

A patient was diagnosed as definite IPA on the basis of histological evidence from biopsy or necropsy material, or as probable IPA on the basis of computed tomography showing radiological features indicative of IPA with or without microbiological confirmation by culture of BAL fluid.

\section{Results}

SENSITIVITY AND SPECIFICITY STUDIES

The sensitivity of the mitochondrial DNA PCR-ELISA was $0.6 \mathrm{fg} / \mathrm{ml}$ for A fumigatus DNA. For the patient study group the sensitivity and specificity, including patients in the probable IPA category, was $100 \%$. Similarly positive and negative predictive values were both $100 \%$ for this patient group. The mitochondrial DNA primers gave amplicons with DNA from $A$ fumigatus, $A$ flavus, $A$ terreus, and $A$ niger but not from any of the other organisms tested (table 1 ).

Table 1 Organisms from which DNA was obtained for use in specificity studies

\begin{tabular}{|c|c|}
\hline Species & Origin \\
\hline Aspergillus fumigatus & $\mathrm{NCPF}^{\star} 2140$ \\
\hline Aspergillus flavus & NCPF 2008 \\
\hline Aspergillus niger & NCPF 2190 \\
\hline Aspergillus terreus & Clinical isolate \\
\hline Aspergillus nidulans & NCPF 2181 \\
\hline Candida albicans & Clinical isolate \\
\hline Tourolopsis glabrata & Clinical isolate \\
\hline Human cytomegalovirus & AD 169 \\
\hline Pseudomonas aeruginosa & Clinical isolate \\
\hline Escherichia coli & Clinical isolate \\
\hline Haemophilus influenzae & Clinical isolate \\
\hline Streptococcus pyogenes & Clinical isolate \\
\hline Streptococcus agalactiae & Clinical isolate \\
\hline Adenovirus & Sigma Biosciences \\
\hline Herpes simplex virus I & Sigma Biosciences \\
\hline Herpes simplex virus II & Sigma Biosciences \\
\hline
\end{tabular}

* National collection of pathogenic fungi, PHLS Mycology Reference Laboratory, Bristol, UK. 
Table 2 Aspergillus mitochondrial PCR results for neutropenic patients with proven and probable invasive pulmonary aspergillosis (IPA)

\begin{tabular}{llllll}
\hline Age/sex & Diagnosis & BAL culture & CT† & $\begin{array}{l}\text { BAL PCR } \\
\text { result }\end{array}$ & Outcome \\
\hline 63/M & AML & A fumigatus + A niger & IPA & Positive & Died \\
47/F & AML & A fumigatus & IPA & Positive & Survived \\
19/M & ALL & Negative & IPA & Positive & Survived \\
$54 / \mathrm{M}$ & AML & C albicans & IPA & Positive & Survived \\
$56 / \mathrm{M}$ & AML & Negative & IPA & Positive & Survived \\
$17 / \mathrm{M}$ & ALL & Negative & IPA & Positive & Survived \\
$52 / \mathrm{M}$ & ALL & C albicans & IPA & Positive & Survived \\
$56 / \mathrm{M}$ & AML & Negative & IPA & Positive & Died \\
24/F & AML & A fumigatus & Not done & Positive & Died \\
$66 / \mathrm{F}$ & My & C albicans & IPA & Positive & Survived \\
49/M & ALL & Negative & IPA & Positive & Died \\
56/F & AML & Negative & IPA & Positive & Survived \\
\hline
\end{tabular}

${ }^{\star}$ Underlying disease responsible for neutropenia: AML, acute myeloid leukaemia; ALL, acute lymphoblastic leakaemia; My, myeloma.

†Computed tomography with features consistent with IPA.

$\ddagger$ Died following recovery from IPA.

|IPA at necropsy. reviewed by Denning and Stevens, ${ }^{19}$ mortality varied from $13 \%$ to $100 \%$ among neutropenic patients, while the mortality in allogeneic bone marrow transplant recipients approached $100 \%$. The early initiation of antifungal treatment, crucial to improving this dismal outcome, relies upon early diagnosis; computed tomography of the thorax and bronchoscopy are useful in this context. Caillot and colleagues reported their experience in 37 neutropenic patients with proven or suspected IPA; the systematic use of computed tomography reduced the time to diagnosis from 7 to 1.9 days, and improved the outcome in IPA. ${ }^{20}$

IPA poses particular diagnostic challenges in neutropenic patients who are unfit for open lung biopsy. The growing numbers of patients who are rendered profoundly neutropenic, often for extended periods of time, the increased use of early pre-emptive antifungal treatment, and the need to evaluate new antifungal agents and treatment for the management of IPA has led to the development of extended case criteria. The characteristic features observed on computed tomography can be used to identify patients with probable invasive aspergillosis which remains unconfirmed by histological evidence. The acceptance and use of use of extended case criteria is essential in order to evaluate new tests and therapeutic strategies for the accurate early diagnosis and effective treatment of invasive aspergillosis in immunocompromised patients.

Several PCR assays using a variety of gene targets have been described for the diagnosis of IPA. Previous publications on PCR assays for aspergillus have reported positivity rates between $15 \%$ and $25 \%$ for non-infected patient groups, including low risk groups. ${ }^{15} 16$ These patients are probably aspergillus PCR positive owing to colonisation of the upper respiratory tract, reducing the positive predictive values for aspergillus PCR for the diagnosis of IPA. This has limited its value for the instigation of treatment. However, the immunocompromised patient group studied here had no evidence of aspergillus colonisation, suggesting rapid progression of invasive disease following colonisation, because of the profound immunosuppression.

The large number of mitochondrial gene PCR-ELISA negative patients in the study group (a proportion of whom had infection with other pathogens) shows the high negative predictive value of the mitochondrial gene PCR-ELISA. The sensitivity approached 100\% for invasive disease. The observed sensitivity and specificity of the mitochondrial PCR assay for disease probably results from the probe primer combination and the solution hybridisation format of the assay. ${ }^{18}$ The ability to speciate the causative organism by the mitochondrial PCR assay, as demonstrated here, is important for a nosocomial pathogen such as aspergillus, with implications for infection control.

The risk of contamination is an important issue for the routine application of any PCR assay and one that can only be controlled, as in this study, by the adoption of rigorous working therapy, or in the wake of bone marrow transplantation, the mortality of established IPA remains appreciable. In the series of 2121 cases 
practices and appropriate decontamination procedures.

We are now at the stage where we have a preliminary routine diagnostic test for the detection of Aspergillus spp, offering a rapid, highly sensitive diagnosis. It ensures early detection of Aspergillus spp and offers the possibility of speciating the pathogen.

We would like to acknowledge the Christie Hospital Endowment Fund for financial support for this project and Dr P Barber for advice and support during the study.

1 Denning DW, Evans EGW, Kibbler CC, et al. Guidelines for the investigation of invasive fungal infections in haematological malignancy and solid organ transplantation. Eur $\mathcal{F}$ Clin Microbiol Infect Dis 1997;16:424-36.

2 Groll A, Shah PM, Mentzel CH, et al. Trends in the postmortem epidemiology of fungal infections in a university hospital. F Infect 1996;33:23-32.

3 Denning DW. Therapeutic outcome in invasive aspergillosis. Clin Infect Dis 1996;23:608-15.

4 Walsh TJ, Lyman CA, Pizzo PA. Laboratory diagnosis of invasive fungal infections in patients with neoplastic invasive fungal infections in patients with

5 Andriole VT. Aspergillus infections: problems in diagnosis Andriole VT. Aspergillus infections: problems

and treatment. Infect Agents Dis 1996;5:47-54.
6 Verweij PE, Donnelly JP, De Pauw BE, et al. Aspergillus infections: problems in diagnosis and treatment. Infect infections: problems in
Agents Dis 1996;5:245-6.

7 Crawford SW, Hackman RC, Clark JG. Open lung biopsy diagnosis of diffuse pulmonary infiltrates after marrow transplantation. Chest 1988;94:949-53.

8 Levy H, Horak DA, Tegtmeir BR, et al. The value of bronchoalveolar lavage and bronchial washings in the diagnosis of invasive pulmonary aspergillosis. Resp Med 1992;86:243-8.
9 Horvath JA, Dummer S. The use of respiratory-tract cultures in the diagnosis of invasive pulmonary aspergillocultures in the diagnosis of invas

10 Duthie R, Denning DW. Aspergillus fungemia: report of two cases and review. Clin Infect Dis 1995;20:598-605.

11 Stynen D, Goris A, Sarfati J, et al. A new sensitive sandwich enzyme-linked immunosorbent assay to detect galactouran in patients with invasive aspergillosis. 7 Clin Microbiol 1995;33:497-500.

12 Manso E, Montillo M, De Sio G, et al. Value of antigen and antibody detection in the serological diagnosis of invasive aspergillosis in patients with hematological malignancies. Eur f Clin Microbiol Infect Dis 1994;13:756-60.

13 Kuhlman JE, Fishman EK, Siegelman SS. Invasive pulmonary aspergillosis in acute leukemia: characteristic findings on CT, the halo sign, and the role of CT in early diagnosis. Radiology 1985;157:611-14.

14 Wheeler JH, Fishman EK. Computed tomography in the management of chest infections: current status. Clin Infect management of chest

15 Spreadbury C, Holden D, Aufauvre-Brown A, et al. Detection of Aspergillus fumigatus by polymerase chain reaction. $\mathcal{f}$ Clin Microbiol 1993;31:615-21.

16 Tang CM, Holden DW, Aufauvre-Brown A, et al. The detection of Aspergillus spp. by the polymerase chain reaction and its evaluation in bronchoalveolar lavage fluid. $\mathrm{Am}$ Rev Resp Dis 1993;148:1313-17.

17 Bretagne S, Costa JM, Marmorat-Khuong A, et al. Detection of Aspergillus species DNA in bronchoalveolar lavage samples by competitive PCR. F Clin Microbiol 1995; 33:1164-8.

18 Davison $\mathrm{E}$, Borrow R, Guiver M, et al. The adaptation of the IS1106 PCR to a PCR-ELISA format for the diagnosis of meningococcal infection. Serodiagn Immunother Infect Dis 1996;8:51-6.

19 Denning DW, Stevens DA. Antifungal and surgical treatment of invasive aspergillosis: review of 2121 published cases. Rev Infect Dis 1990;12:1147-201.

20 Caillot D, Casasnovas O, Bernard A, et al. Improved management of invasive pulmonary aspergillosis in neutropenic patients using early thoracic computed scan and surgery. f Clin Oncol 1997;15:139-47. 